\title{
RESPUESTA A: COMENTARIOS SOBRE EL ARTÍCULO "EVALUACIÓN DE LAS TÉCNICAS DE CAPACITACIÓN ESPERMÁTICA Y SU EFECTO EN LA FRAGMENTACIÓN DEL ADN"
}

\section{Answering to Comments on "Assesment of sperm capacitation techniques and their effect on DNA} fragmentation"

Ibagué, diciembre 21 de 2012

\section{Señor editor \\ Doctor Hernando Gaitán, MD, MSc}

\section{Respetado doctor Gaitán}

Ante todo quisiera agradecerle al PhD Walter Cardona por el interés dado a la investigación y al artículo publicado, ya que con este tipo de ejercicios podemos aclarar conceptos, ofrecer mayor información y avanzar en el conocimiento de este campo de la ciencia.

Teniendo en cuenta la opinión del PhD Cardona, quisiera aclarar que la capacitación espermática es un proceso en donde los espermatozoides sufren cambios moleculares que les permiten alcanzar el ovocito y posteriormente fertilizarlo (1), y que los mecanismos involucrados han sido estudiados basándose en ensayos in vitro específicamente (2), por tanto, es un proceso que puede ser simulado in vitro (3) utilizando técnicas como swim up y gradientes de densidad, así como también, medios de cultivo específicos que promuevan este proceso (4).

Las dos técnicas utilizadas en la investigación tienen como función la separación de espermatozoides móviles así como su capacitación. Asimismo, se ha comprobado que el lavado y la posterior recuperación de espermatozoides están relacionados con la capa- citación de los gametos masculinos (5), lo que puede significar que de manera in vitro se da la capacitación de los espermatozoides por swim up y gradientes de densidad. Es así como estas dos técnicas se aplican en laboratorios de Andrología y Embriología para tratamientos como inseminación intrauterina, FIV e ICSI (6).

Además de su principio físico, en las técnicas de capacitación espermática se debe tener en cuenta la composición de los medios de cultivo para conseguir las dos funciones anteriormente nombradas. Recientemente se suplementaron los medios de cultivo con albúmina sérica (humana y bovina), no solo porque reduce el riesgo de transmitir infecciones sino porque se ha encontrado que es adecuada para la preparación del semen en los tratamientos de reproducción asistida (4), al facilitar la capacitación, la reacción acrosomal y la fertilización in vitro (2). Esta proteína favorece la remoción de colesterol de la membrana plasmática, es decir, facilita el flujo de colesterol requerido para la capacitación (7).

Reconozco que es de gran importancia dar a conocer los medios de cultivo utilizados. Para la capacitación por swim up se usó medio HTF modificado (Irvine Scientific, Santa Ana, CA) que contiene sales, proteínas y aminoácidos utilizados para la manipulación de gametos y cultivo de embriones (insertos disponibles 
en la página web de Irvine) suplementados al 10\% de sustituto de suero sintético (SSS) (Irvine Scientific, Santa Ana, CA) que contiene aproximadamente 84\% de albúmina sérica humana, entre otros componentes.

Para la capacitación por gradientes se usó Isolate (Irvine Scientific, Santa Ana, CA), una suspensión coloidal de partículas de sílice (8). Posteriormente, para el segundo lavado se usó medio HTF modificado suplementado al 10\% de SSS.

Finalmente, en lo que respecta a la movilidad, Gilbert (3) afirma que hay una gran controversia en este aspecto, ya que existen teorías sobre el desplazamiento del espermatozoide hacia el ovocito en la trompa de Falopio, probablemente el gameto femenino atraiga al masculino por quimiotaxis, o tal vez el espermatozoide es transportado por actividad muscular del útero. Sin embargo, en el artículo solo se menciona que después de la capacitación espermática la calidad seminal mejora en cuanto a movilidad, morfología y disminución de la fragmentación del ADN de los espermatozoides.

Agradezco la atención prestada

\section{Luisa Fernanda Calderón-Mendoza Bióloga luisa.fernanda.cm@hotmail.com}

\section{REFERENCIAS}

1. Coopet T, Yeung C. Physiology of Sperm Maturation and Fertilization. En: Nieschlag E, Behre H, Nieschlag
S, editors. Andrology Male Reproductive Health and Dysfunction. $3^{\text {rd }}$ edition. London: Springer; 2010. p. 74-78.

2. De Jonge C. Human Fertilization. En: Keel B, May J, De Jonge C, editors. Handbook of the Assisted Reproduction Laboratory. Florida: CRC Press; 2000. p. 2-8.

3. Gilbert S. Biología del desarrollo. 7 ed. Buenos Aires: Editorial Médica Panamericana; 2005.

4. Bourne H, Archer J, Edgar D, Baker HW. Sperm Preparation Techniques. En: Gardner D, Weissman A, Howles C, Shoham Z, editors. Textbook of Assisted Reproductive Technologies Laboratory and Clinical perspectives. 3 edition. United Kingdom: Informa Healthcare; 2004. p. 53-57.

5. Selles E, Pérez I, Pellicer J, López M. Capacitación espermática. En: Remohí J, Romero J, De los Santos M, Pellicer A, editors. Manual práctico de esterilidad y reproducción humana. Laboratorio de Reproducción Asistida. 3 ed. España: McGraw Hill; 2008. p. 25-29.

6. Penna-Videau S. Selección de espermatozoides para técnicas de reproducción asistida. En: Urbina M, Lerner J, editors. Fertilidad y Reproducción Asistida. Caracas: Editorial Médica Panamericana; 2008. p. 485-89.

7. Gadella B, Visconti P. Regulation of capacitation. En: De Jonge C, Barrat C, editors. The Sperm Cell. Cambridge: Cambridge University Press; 2006. p. 134-46.

8. Makkar G, Ng H, Yeung S, Ho P. Comparison of two colloidal silica-based sperm separation media with a nonsilica-based médium. Fertil Steril 1999;72:796-802. 